\title{
Research on the Construction of National Central City Comprehensive Transportation Hub-Taking Chengdu City as an Example
}

\author{
Ting Wang ${ }^{1}$ \\ ${ }^{1}$ School of Public Affairs \& Law, Southwest Jiao Tong University, Chengdu 610031, China;
}

Keywords: National central city; transportation hub; Chengdu

\begin{abstract}
The transportation hub is the platform that the national central city plays the role of agglomeration and radiation, which is also the foundation for the development of national central city. Analyzing the radiation range of Chengdu's expressway, railway and aviation, this paper can determine the location of Chengdu's comprehensive transportation hub. In order to further expand its hub function and enhance its international status, this paper proposes to build the hub of international railway and international aviation, strengthen coordinated development, and optimize the urban agglomeration transportation network system.
\end{abstract}

\section{Introduction}

The national central city is the product that the national political and economic elements gather to the cities. On the one hand, it is a significant region and gateway for the country to participate in global competition and international exchanges. On the other hand, it is also a central city that plays a leading, agglomerating and radiating function in the region. In 2005, the Ministry of Housing and Urban-Rural Construction of China put forward the concept of national central city for the first time in compiling the National Urban System Planning. From National Urban System Planning (2010-2020) to the Guangzhou Plain Urban Agglomeration Development Plan, China has clearly put forward the planning for the construction of nine national central cities, namely, Beijing, Tianjin, Shanghai, Guangzhou, Chongqing, Chengdu, Wuhan, Zhengzhou and Xi'an. In the list of established national central cities, each city is involved to function as a comprehensive transport hub. Hub is the material channel of the flow of people, commodity, capital and information. It is a bridge linking state to the world [1].Chengdu, as one of the representatives of the national central cities in the Inland areas, is of great strategic significance, which shoulders the national mission, leads the development of the western region and represents the national image. What's more, it plays a key role in the function of transportation hub in the western inland.

\section{Literature Review}

There is no mention of national central city in foreign countries, but some of their super-large central cities actually play the role of National Central city. Foreign scholars use the world cities or global cities to describe the core cities which have important influence and control in the whole world. However, Chinese scholars have not yet formed a unified understanding of the national central cities, mainly forming four views: First, from the perspective of the urban system to define the world city, the national central city is one of the levels. Secondly, from the perspective of global urban network formed by the interaction of globalization and informatization, the energy level of node cities is determined by the network flow and influence scope. Third, define the national central city from the perspective of national urban system or key urban agglomeration planning. Fourth, define the national central city from the perspective of market choice and function decision [2]. The essence of a national central city lies in its function. It has the functions of guiding innovation, radiation allocation, city service and comprehensive [3].According to the book Foreign Capital and Urban Development, the national central city has the function of agglomeration, diffusion and innovation [4]. The internal functions of national central city mainly embodied in the functions that the central city undertakes to meet the local residents' production, living and development in the process of resource utilization, environmental protection, public services, improvement of people's livelihood and so on; External functions are mainly embodied in economic functions [5]. At present, there are three methods for the comprehensive evaluation of national central cities: First, the evaluation criteria should be based on a single indicator or a 
few consensus indicators. Second, a functional index system that only emphasizes one or more items is established. Third, a comprehensive index system is established [6]. In the practice research of national central cities, Liu Huake's paper proposed three ways to speed up the construction of Zhengzhou as a national center city, namely, to focus on the comprehensive pilot area of the airport, to build the core position of important transportation hub at home and abroad, and to cultivate strategic emerging industries [7].

To sum up, the academic circles for the National Center City research results are more fruitful, but for the National Center City transportation hub this specific aspect of research, the results are not many. This paper attempts to discuss the related problems of Chengdu's comprehensive transportation hub as a national central city, aiming to determine the location of Chengdu's comprehensive transportation hub and put forward feasible suggestions and measures by analyzing the radiation range of various transportation modes in Chengdu.

\section{Radiation Range Analysis of Chengdu Comprehensive Transportation Hub}

The function of comprehensive transportation hub in national central cities is mainly reflected in the radiation capacity around the world. The radiation range is wider; the influence and driving force is stronger. Chengdu is a vital hub connecting southwest China with eastern, northern and southern China, and has the characteristics of inland comprehensive transport hub construction. Its external traffic, including roads, railways and aviation, is a key part of the city's radiation capacity.

\subsection{Expressway radiation range.}

By the end of 2017, the total mileage of Chengdu expressway was $26294 \mathrm{~km}$, of which $959 \mathrm{~km}$ of expressways. There are 13 national expressways in Chengdu, such as Beijing-Kunming Expressway, Shanghai-Chengdu Expressway, Xiamen-Chengdu Expressway, Chengdu-Chongqing Ring Expressway, etc. Chengdu has formed "diamond economic circle" highway skeleton, including Chengdu, Chongqing, Xi'an, Kunming and Guizhou. It has been built to Chongqing 3-hour expressway traffic circle, to the surrounding provincial capital city 8-hour expressway traffic circle, to Beijing-Tianjin-Hebei, Pearl River Delta and Yangtze River Delta region 20-hour expressway traffic circle. It has formed a national expressway network connecting Chengdu Chongqing city group, the middle and western part of China, and the whole country.

Chengdu expressway has formed a circular and radial highway layout form centering on Chengdu, which strengthens the connection and communication between various districts and counties, making the interchange of urban traffic of each Expressway more and more convenient. At the same time, it has greatly reduced the time cost of arriving at cities in all provinces of the country, to a certain extent; it also alleviates the traffic congestion of the main arteries and ensures the accessibility of the traffic.

\subsection{Railway radiation range.}

In 2017, China Railway Corporation and Sichuan Provincial People's Government approved the "Chengdu Railway Hub Plan (2016-2030)" and planned to form a large radial hub connecting Xi'an, Chongqing, Guiyang, Kunming, Xining (Lanzhou), Lhasa and Dazhou in eight directions and 13 trunk lines. Fully integrated into the national high-speed railway network, 1 hour to Chongqing, 4 hours to Wuhan, Xi'an, Guiyang, Kunming, Changsha, 6 hours to Lanzhou, Xining, 8 hours to Beijing, Shanghai, Guangzhou. The branch line of Ziyang North Station of Chengdu-Chongqing High-speed Railway is planned and constructed, and the Chengdu-Chongqing High-speed Railway is introduced into Tianfu International Airport to enlarge the radiation range of Tianfu Airport.

The opening of Chinese and European trains has further expanded the international market of Chengdu railway's radiation. In 2013, Chengdu-Europe Express Railway started from Qingbaijiang, Chengdu, and formed a $9000 \mathrm{~km}$ west to logistics open channel. Qingbaijiang District Container Center Station has become the largest railway container center station in Asia. In 2017, Chengdu-Europe Express Railway opened 1012 trains, ranking first in the country. Chengdu-Europe Express Railway accounted for 23.4\% of China-Europe's total trains. Nowadays, Chengdu-Europe Express Railway has been opened one after another from Chengdu to Rhodes, Nuremberg, Tilburg, Moscow, Prague, Milan, ASEAN International Sea-Rail Intermodal 
Transport Channel, and takes the lead in constructing a Y-shaped international logistics channel from Chengdu to the hinterland of Europe, north to Russia and south to ASEAN.

\subsection{Aviation radiation range.}

Chengdu Shuangliu International Airport has opened a number of routes and its distribution is wide. By the end of January 2018, Chengdu Shuangliu International Airport had 317 routes, including 193 domestic routes and 106 international routes, reaching five continents in the world. Chengdu to Beijing routes ranked as the world's 20 busiest routes in 2017, Chengdu is the only central and western region of China on the list of the busiest route destination city. According to the data, the annual passenger throughput of Chengdu Shuangliu International Airport in 2016 was 42.239 million, ranking 27 in the international airport; in 2017, the annual passenger throughput was 49.8 million, ranking fourth in the country.

Chengdu is the third city in mainland China to be approved to construct double airports after Beijing and Shanghai. It is also the backbone of the national intermodal transport hub city and international comprehensive transport hub. It develops international aviation hub relying on Shuangliu International Airport and Tianfu International Airport, providing a new platform for the flow of goods, services, capital and technology in larger space. Besides, Chengdu has a large number of airline bases and has the capability of serving as an aviation hub. Chengdu Shuangliu International Airport has become the only Midwest route covering five continents in the world, and is the airport with the most European and Middle East routes. From this we can see that the radiation range of Chengdu aviation is still relatively large.

\section{Function Orientation of Chengdu Comprehensive Transportation Hub}

The function of comprehensive transportation hub of national central city affects other functions to a certain extent. Therefore, based on the analysis of the radiation range of Chengdu comprehensive transportation mode, the function is positioned.

First, Chengdu is a significant comprehensive transportation hub in the western region, forming a radial and ring-shaped traffic layout with Chengdu as the center. The city is located in the southwest of China. Although it is close to Chongqing, it has formed its own unique comprehensive transportation hub, and has become one of the important growth poles of economic development in the southwest of China.

Second, the railway transport in Chengdu has obvious advantages. Qingbaijiang District Container Center Station has become the largest railway container center station in Asia. The number of Chengdu-Europe Express Railway ranks first in the country. Express railway of China to other Asian countries has opened one after another, forming a major road for international transportation. At the same time, Chengdu is at the junction of The Belt and Road and the Yangtze River economic belt, and has the geographical advantages of connecting multiple channels. It further increases Sichuan's competitiveness in opening up to Asia and Europe.

Thirdly, the influence and radiation range of air transport in Chengdu is gradually expanding, and it can play a pivotal role in the southwest, the whole country and even in the world. In terms of geographical location, hinterland support and basic conditions, there are certain advantages in three conditions. In terms of geographical location, Chengdu is located in the center of Eurasia. Compared with the central and eastern regions of China and Southeast Asia, Chengdu has the advantage of time-effect, and is suitable for opening the routes of Eurasia and Oceania. In terms of hinterland support, the $1000 \mathrm{~km}$ hinterland around Chengdu has a population of more than 500 million and a GDP of more than 15 trillion. It can radiate Southeast Asia and have a stable supply of passengers and goods. In terms of basic conditions, Chengdu Shuangliu International Airport has built two runways and two terminal buildings to realize the integration of customs clearance. It has initially established an international airline network for Southeast Asia and East Asia, directly to Europe and North America. At the same time, Tianfu International Airport has been approved and is speeding up construction. Chengdu has become the only city in the central and western regions with "one city, two fields".

Comprehensive transportation hub in Chengdu is basically established, and its function is becoming more and more powerful, which makes Chengdu further expand the scope of global links and services, enlarges the radiation and influence of Chengdu, and promotes its international status. 


\section{Measures for Building Comprehensive Transportation Hub in Chengdu}

\subsection{Accelerating the construction of international railway hub}

As an inland city, Chengdu's internationalized transportation network system has become the key support for integrating into the global industrial division of labor system. Promoting the level of industrial development; expanding international influence, including the right to speak in the field of international transportation, the formulation of international transport rules, so as to improve the level of transportation output. Therefore, Chengdu should take measures to build an international railway freight hub by expanding freight corridors and enhancing the radiation capacity of the hinterland. The one is to open up the foreign freight transport channel and optimize the commissioning plan of Chengdu-Europe Express Railway. The two is to radiate the major urban agglomerations in China. By speeding up the construction of Longchang-Huangtong Railway and Chengdu-Kunming Railway, the sea passage to Fangcheng Port and Nansha Port will be opened, and the interconnected and interchangeable train will be expanded to domestic cities. The three is to build a "one core, multi zone" international railway port. Relying on the four main railway freight yards (Chengxiang Station, Dawan Station, Xinjin Station, Huaizhou Station), as well as the storage area, trade area, supporting area and other functional areas around the station, Chengdu will create an international railway port with "one nuclear and multi-zone" and strengthen regional organizational capacity. The four is to improve service quality and provide efficient and convenient port service for enterprises. Optimizing the single-window and one-stop service, perfecting the comprehensive logistics information service platform of Chengdu International Railway Port, improving the service quality of train and train transportation, exploring the mode of consolidation and transportation, and promoting regional cooperation by giving full play to the advantages of Chengdu-Europe Express Railway and building regional cooperation relations.

\subsection{Accelerating the development of international aviation hub}

The development of air transport has certain advantages and conditions. Through the construction of intercontinental portal hub airport and expanding the radiation capacity of the hinterland, it can create an international air hub. The first is to strengthen the energy level of aviation hub. Based on the development advantages of the two airports, the "one city, two airports" aviation pattern of Tianfu International Airport and Shuangliu International Airport should be strengthened to upgrade the energy level of the aviation hub. The two is to build Eurasia transit hub. Taking advantage of the location advantages, the international direct flights to Europe, Southeast Asia and Oceania will be encrypted to form an international route network covering five continents: Europe, the United States, Australia, Africa and Asia. The three is to encrypt the hinterland route network. Focus on strengthening domestic and Southeast Asian routes covering 500-1000 kilometers, and improving the medium and short distance routes network in the hinterland around the radiation. The four is to improve the connecting between aviation and railways. Through the "two vertical and one horizontal" high-speed rail corridors, integrated into the national "eight vertical and eight horizontal" high-speed rail network, the four-hour connection between Xi'an, Kunming, Guiyang, Lanzhou, Wuhan and other cities will be realized, the hinterland of the central and western regions will be expanded, and the seamless connection between the aviation hub and the high-speed rail hub will be realized through the track line.

\subsection{Optimizing the transportation network system of Urban Agglomeration}

Chengdu is located in the Chengdu-Chongqing urban agglomeration, and Chengdu and Chongqing have become the most important two development poles of the Chengdu-Chongqing urban agglomeration, and give full play to its dual-core driving function. First is give priority to the construction of interring city transportation network. We will build an inter-city transportation network backed by high-speed railways, inter-city railways and expressways, and create a traffic circle between the core cities, between the core cities and the surrounding cities, and between the adjacent cities for one hour. Two is to strengthen the comprehensive transport hub construction. According to the requirement of "zero-distance transfer and seamless connection", we should strengthen the organic connection of transportation modes such as water transport, railway, highway, aviation and pipeline, and lay stress on the development of Chengdu's national comprehensive transportation hub. Three is to strengthen the comprehensive transport hub construction. 
According to the requirement of "zero-distance transfer and seamless connection", Chengdu should strengthen the organic connection of transportation modes such as water transport, railway, highway, aviation and pipeline, lay stress on developing Chengdu's national comprehensive transportation hub, actively build regional comprehensive transportation hub such as Luzhou and Nanchong, and improve the operational efficiency of the comprehensive transportation system. We will improve the level of integrated passenger transport hub, improve the function of freight transport hub, and promote the construction of urban logistics parks, logistics centers and distribution centers.

\section{Conclusion}

Transportation hub has comprehensive characteristics, which is the foundation for the development of national central cities. The comprehensive transportation hub of Chengdu should not be confined to the western region of China, but should serve the whole country, even the whole world. Therefore, on the basis of the current transport development and a wider range of leading role, Chengdu needs to further strengthen the construction of international railway and international aviation hub, two-wheel drive. At the same time, based on the Chengdu-Chongqing urban agglomeration, strengthen the coordinated development, and optimize the transportation network system, so that the function of Chengdu traffic hub and the name of the national center city more matched.

\section{References}

[1]. Deng Chunyu, "Strategic Analysis of Guangzhou National Central City Based on the Matching of External Economic Relations and Geo-economics Relations,” Geographic Science, vol. 3, pp.329-335, June 2009.

[2]. Zhou Yang, “National Central City: concept, characteristics, functions and evaluation,” City observation, vol. 1, pp.132-142, February 2012.

[3]. Tian Meiling, Liu Siming, and Zhu Yuanyuan, "Comprehensive Evaluation and Empirical Study of National Central Cities: A Case Study of Wuhan," Scientific and Technological Progress and Countermeasures, vol. 11, pp.117-121, June 2013.

[4]. Wang Wei, Foreign capital and urban development, Beijing: China business press, 2007, pp. 32-33.

[5]. Li Lin, "Function selection and implementation path of National Central City,” City, vol. 10, pp.17-21, October 2011.

[6]. Tian Meiling and Fang Shiming, “A summary of the research on national central cities,” international urban planning, vol. 2, pp.71-74, April 2015.

[7]. Liu Huake. "The Strategic Significance and Path Choice of Zhengzhou's Construction of a National Central City” National Circulation Economy, volume 21, pp.51-52, July 2017. 